\title{
Seroprevalence of rubella in pregnant women
}

\author{
Sumeet R. Tripathy ${ }^{1}$, Aruna Menon ${ }^{1}$, Bikram Bhardwaj ${ }^{1}$, Mohammed Ashraf Ali S. Namaji ${ }^{2 *}$, \\ Nilesh A. Khardenavis ${ }^{1}$, Neha Gupta ${ }^{1}$
} ${ }^{1}$ Department of Obstetrics and Gynecology, ${ }^{2}$ Department of Microbiology, Armed Forces Medical College, Pune,
Maharashtra, India

Received: 05 October 2021

Accepted: 30 October 2021

\section{*Correspondence:}

Dr. Mohammed Ashraf Ali S. Namaji,

E-mail: ashrafnamaji@gmail.com

Copyright: ( ) the author(s), publisher and licensee Medip Academy. This is an open-access article distributed under the terms of the Creative Commons Attribution Non-Commercial License, which permits unrestricted non-commercial use, distribution, and reproduction in any medium, provided the original work is properly cited.

\begin{abstract}
Background: Rubella is a droplet infection characterized by self-limiting illness. However infection during pregnancy may result in miscarriage, congenital birth defects leading to long term morbidity. The aim of the study was to estimate the seroprevalence of rubella immunity in pregnant women.

Methods: Antenatal patients, irrespective of period of gestation, fulfilling the inclusion criteria were tested for rubella IgG antibodies.

Results: A total of 258 pregnant women were included in the study. The estimated seroprevalence of immunity against Rubella infection was $70.5 \%(n=182)$ whereas $29.5 \%(n=76)$ were seronegative and thus susceptible to rubella infection. The distribution of seroprevalence of rubella immunity based on age group and gravidity were also evaluated.

Conclusions: The results reveal high level of rubella sero positivity, which indicates continued transmission of rubella infection in the community.
\end{abstract}

Keywords: Congenital rubella syndrome, Rubella, Rubella containing vaccine, Seroprevalence

\section{INTRODUCTION}

Rubella virus is a RNA virus of the Togaviridae family. It is a droplet infection characterized by a self-limiting illness with fever, rash and lymphadenitis, or can be subclinical. However infection during early pregnancy may result in miscarriage, congenital birth defects leading to long term morbidity. Approximately 100,000 children are still born with CRS (congenital rubella syndrome consisting of congenital cataract, micropthalmia and cardiac defects and sensorineural deafness) worldwide as per the World Health Organization estimates. ${ }^{1}$ Analysis of seroprevalence based statistical model indicates 46,621 births of infants with CRS annually in the south-east Asian Region (SEAR) during 2000-2009. ${ }^{2}$ A study conducted by World Health Organization (WHO), in developing countries showed $10-25 \%$ of the women tested were seronegative. ${ }^{3}$ It is well known that a susceptibility of even $10 \%$ can lead to outbreak of congenital rubella syndrome. ${ }^{4}$ The near total vaccination coverage in America and
Europe has caused a drastic elimination of both the virus as well as CRS in population. On the other hand, the highest risk of CRS is found in countries like India, where the RCV (rubella containing vaccine) was not introduced in the national vaccination program or the vaccine coverage is low. Rubella infection is subclinical in upto $60 \%$ cases and susceptibility to infection can be determined only by serological tests. ${ }^{5,6}$ Only a few studies regarding the seroprevalence or susceptibility to Rubella in Indian population have been done. A few seroepidemiological studies have revealed that significant number of women conceive without immunity against rubella, and are thus susceptible to rubella infection in pregnancy and its adverse effects. ${ }^{5,7}$

Although a vaccine is available against rubella, the same has not been incorporated in universal immunization program in India. There is no data regarding total burden or susceptibility to rubella infection in India. However a few studies have been done, mainly in northern India, 
assessing rubella immunity. ${ }^{8-11}$ The aim of this study was to assess the sero-prevalence of rubella immunity in Pune, in western Maharashtra.

\section{METHODS}

A cross-sectional descriptive study was carried out from January 2021 to March 2021 at antenatal OPD of a tertiary care hospital in Pune, Maharashtra with prior approval from institutional ethical committee.

\section{Inclusion criteria}

The study included pregnant women of any period of gestation or parity attending antenatal OPD.

\section{Exclusion criteria}

Pregnant women with known prior rubella immunization status were excluded.

Participants were enrolled and sample collection was done after an informed consent. The estimated prevalence of rubella immunity based on review of literature was $80 \%$. With $95 \%$ confidence interval and $5 \%$ precision, the sample size was calculated to be 246 . It was decided to include 250 participants. Data collection and sample collection was done on antenatal OPD days. Detailed obstetric history was taken.

\section{Sample processing}

Five millilitres of whole blood was collected in a vacutainer with gel separator under aseptic precautions. Sample was collected only once from each study participant. The serum was separated and stored at $-20^{\circ} \mathrm{C}$. Commercially available rubella $\operatorname{IgG}$ ELISA kit (CalBiotech, CA 92020 USA) was used for qualitative estimation of $\mathrm{IgG}$ antibody to rubella in human serum. All the kits used were of the same lot. Cut-off value (COV) and antibody index value (ratio of sample OD/COV) was calculated for each sample. Antibody index results were interpreted as positive $(>1.1)$, negative $(<0.9)$ and equivocal (0.9-1.1) as per the kit literature. Quality control was carried out by use of one positive control, one negative control and a calibrator with each run.

\section{RESULTS}

A total of 280 consecutive non-repeat antenatal patients were screened, of which 10 patients were unwilling to participate in the study. 05 patients gave definite history of Rubella vaccination and hence were excluded. 07 samples were lysed at the time of testing. Estimation of IgG was done on 258 samples.

\section{Demographics}

The mean age was 28 (SD 4.13) ranging from 19 to 42 years. The age wise distribution of participants immune against rubella and the susceptible participants is given in Table 1. Of the 258 samples analysed, 53 were in first trimester, 90 in second trimester and 115 in $3^{\text {rd }}$ trimester. The IgG was positive in 182 patients $(70.54 \%)$ and negative, thus susceptible, in $29.46 \%$. The distribution of the immune and susceptible participants based on gravidity is shown in Table 2. Among women with prior abortions $(n=85), 65(76.4 \%)$ were rubella IgG positive. There was one participant who gave history of sensorineural hearing loss in first child and was rubella IgG positive. However no statistically significant correlation can be drawn between age, parity and susceptibility to rubella from the available data.

Table 1: Distribution of participants based on age.

\begin{tabular}{|llll|}
\hline Age (years) & Positive & $\%($ CI \%) & Negative \\
\hline $\mathbf{2 0}$ & 2 & $100(100-100)$ & - \\
\hline $\mathbf{2 1 - 2 5}$ & 52 & $72.2(61.9-82.6)$ & 20 \\
\hline $\mathbf{2 6 - 3 0}$ & 80 & $69.6(61.2-78)$ & 35 \\
\hline $\mathbf{3 1 - 3 5}$ & 41 & $69.5(57.7-81.2)$ & 18 \\
\hline $\mathbf{3 6 - 4 0}$ & 6 & $66.7(35.9-97.5)$ & 3 \\
\hline$>\mathbf{4 0}$ & 1 & $100(100-100)$ & - \\
\hline Total & 182 & $70.5(65-76.1)$ & 76 \\
\hline
\end{tabular}

Table 2: Distribution of participants based on gravidity.

\begin{tabular}{|llll|}
\hline Gravida & Positive & $\%($ CI \%) & Negative \\
\hline Primigravida & 68 & $65.4(56.2-74.5)$ & 36 \\
\hline Gravida 2 & 79 & $72.5(64.1-80.9)$ & 30 \\
\hline Gravida 3 & 22 & $75.9(60.3-91.4)$ & 7 \\
\hline $\begin{array}{l}\text { Garvida 4 } \\
\text { and more }\end{array}$ & 13 & $81.3(62.1-100.4)$ & 3 \\
\hline Total & 182 & $70.5(65-76.1)$ & 76 \\
\hline
\end{tabular}

Table 3: Seroprevalence of rubella IgG in pregnant women from different geographical locations in India.

\begin{tabular}{|c|c|c|c|}
\hline Author & Place & Year & $\begin{array}{l}\text { Rubella } \\
\text { IgG } \\
\text { positivity }\end{array}$ \\
\hline Gupta et al $^{8}$ & New Delhi & 2004 & $87 \%$ \\
\hline Gupta et al $^{10}$ & $\begin{array}{l}\text { Lucknow, Uttar } \\
\text { Pradesh }\end{array}$ & 2013 & $88.2 \%$ \\
\hline $\begin{array}{l}\text { Jayakrishnan } \\
\text { et al }{ }^{11}\end{array}$ & $\begin{array}{l}\text { Kozhikode, } \\
\text { Kerala }\end{array}$ & 2016 & $94.3 \%$ \\
\hline Muliyil et al $^{12}$ & $\begin{array}{l}\text { Multicentric } \\
\text { Jodhpur } \\
\text { Rajasthan, } \\
\text { Vellore Tamil } \\
\text { Nadu, Bengaluru } \\
\text { Karnataka, } \\
\text { Chandigarh, } \\
\text { Jamshedpur } \\
\text { Jharkhand }\end{array}$ & 2018 & $83.4 \%$ \\
\hline Pandya et $a^{21}$ & Vadodara, Gujarat & 2019 & $88.9 \%$ \\
\hline Present study & Pune, Maharashtra & 2021 & $70.54 \%$ \\
\hline
\end{tabular}




\section{DISCUSSION}

Sero-surveillance is an important component in the attempt to achieve rubella control. Our study indicates a prevalence of rubella immunity in $70.54 \%$ of the study population. In similar studies carried out in other parts of India showed a prevalence of immunity between 70-90\% (Table 3). ${ }^{8,10-12}$ A high seroprevalence indicates acquisition of natural immunity against rubella in absence of vaccination which, in turn, indicates ongoing transmission of virus.

The mean age of participants in our study was 28 (SD 4.13) with maximum participants in 26-30 years age group $(\mathrm{N}=115,44.5 \%)$. The prevalence of immunity in this age group was $69.5 \%$ and thus the susceptible population was $30.5 \%$. In a study conducted by Mulliyil et al however the susceptible population in this age group was $15.1-15.9 \% .^{12}$

The relationship of rubella immunity based on gravidity of participants was also assessed. Majority of patients were either primigravida $(\mathrm{N}=104,40.3 \%)$ or second gravida $(\mathrm{N}=109,42.2 \%)$. The seroprevalence of rubella immunity was 65.4 and $72.5 \%$ respectively and thus the susceptible population was $34.6 \%$ in primigravida and $27.5 \%$ in second gravida.

We also calculated the prevalence of immunity based on the trimester of pregnancy. The majority of our patients were in the $3^{\text {rd }}$ trimester $(\mathrm{N}=115,44.5 \%)$. The prevalence of susceptible population was $30.4 \%$.

Rubella infection is a self-limiting infection with an uncomplicated clinical course and no residual effects. Natural infection provides lifelong immunity. However infection occurring in the first trimester of pregnancy can have far reaching consequences causing significant morbidity. Classically described as congenital rubella syndrome (CRS), it is characterized by ocular defects (congenital cataract commonest), auditory defects (sensorineural hearing loss), cardiovascular and central nervous system defects.

The mechanism causing these defects are mainly due to effect of rubella virus induced cellular damage and effect of virus on dividing cells. Rubella embryopathy is characterized by cellular necrosis without any inflammatory response. ${ }^{13}$ Rubella reinfection is fairly uncommon and is unlikely after immunity acquired following infection. Risk of reinfection during first trimester is reported between $5-10 \% .^{14}$

The public health importance of rubella stems from the fact that although self-limiting, infection during early pregnancy can have far reaching consequences by CRS. The primary means of prevention of CRS is by rubella vaccination. Rubella vaccine is safe and effective and the strain used is RA27/3. There are two described approaches for rubella vaccination-immunization of all reproductive age group women with intent to eliminate rubella and immunization of reproductive age group women and children- with intent to eliminate rubella as well as CRS. ${ }^{15}$

In a study conducted by Muliyil et al across six hospitals in India and including 1800 participants, the seroprevalence ranged from $77.7 \%$ to and $88.7 \%$ in various parts of India which is higher than the results of our study. ${ }^{12}$ The prevalence of susceptibility in our study was around $30 \%$. It is pertinent to note that earlier serosurveys conducted in India has put in a range of $2 \%$ to $38 \%$, which is a very wide range. ${ }^{8-12}$

Rubella infection predominantly affects childhood age groups but given the large population of India, even a susceptibility of $30 \%$ amongst the young pregnant population can lead to a high load of CRS cases. This is because in the presence of ongoing transmission in community, the susceptible pregnant patient is likely to be inflicted by rubella infection thereby leading toits sequelae. This finding is also supported by CRS sentinel screening done in a few cities. ${ }^{12,16}$

In India, rubella vaccination was not a part of the universal immunization program, but the vaccination was available in the private sector for more than 20 years. Hence it can be safely said that there is a skewed populace amongst the young reproductive group that is immunized against Rubella by vaccination. On the other hand, high incidence of immunity in the young population shows active transmission of the virus is still prevalent and hence the population is at risk of having larger numbers of rubella amongst the susceptible young population and a proportionate increase in CRS cases.

Vaccination has now been included in the routine immunization program in India since 2017 after a pilot project carried out in a few states.

It is also a matter of discussion that the practice of immunizing only the female children as was done in a few countries would continue to keep the chain of transmission active through the adolescent male population and hence a case can be made for immunization of all children irrespective of gender.

Low level rubella containing vaccine (RCV) coverage among children over several years can result in increase of CRS incidence by increasing the average age of infection without sufficiently reducing rubella incidence. ${ }^{17}$ If childhood RCV coverage falls below a critical threshold, then it actually increases incidence of CRS. ${ }^{18,19}$ Analysis by Winter et al have showed that low level vaccine coverage increases CRS incidence by around 5\% as compared to no vaccination. ${ }^{17}$ Various epidemiological and mathematical models have examined childhood rubella immunization programs and have recommended that at least $80 \%$ coverage is required to avoid long term increase in CRS incidence. ${ }^{17}$ In India rubella vaccine has been available for around two decades (as MMR vaccine). 
However it was only in 2017 that it has been introduced in routine immunization program. ${ }^{20}$ Our study showed a susceptibility rate of $29.5 \%$ which is higher than other similar studies done in India as shown in Table 3. This further emphasizes on the need for rubella vaccination.

The strength of this study was that its simple methodology which can be applied for large scale studies to assess the seroprevalance of rubella immunity. The relatively higher prevalence of susceptible population highlights the need for rubella vaccination in reproductive age group women. However the limitation of this study is the small numbers. It also catered largely to an urban population.

\section{CONCLUSION}

The lack of information regarding the epidemiology of rubella infection limits intervention efforts that would limit the vertical transmission. This study addresses this issue and confirms that there is ongoing transmission and endemicity of rubella in the study population.

A case is also definitely made for prenatal screening of prospective mothers for rubella immunity and vaccinating the susceptible ones prior to pregnancy, thereby decreasing the chances of CRS appreciably. This is further justified by the fact that RCV was introduced in Indian National Immunisation program in 2017 in a phased manner. Subsequent campaigns aimed at vaccinating the teenage group. However the population presently in reproductive age group has missed out on the vaccine campaign and thus susceptible to Rubella infection and would definitely benefit from Rubella vaccination in the pre-conceptional period.

A multipronged approach through integration between community/preventive medicine, pediatrics and obstetrics and gynaecology authorities would go a long way in minimizing the numbers of CRS.

Funding: No funding sources Conflict of interest: None declared

Ethical approval: The study was approved by the Institutional Ethics Committee

\section{REFERENCES}

1. World Health Organization, Regional office for South-East Asia. Strategic Plan for Measles Elimination and Rubella and Congenital Rubella Syndrome Control in the South-East Asia Region 2014-2020. Available from: https://apps.who.int/iris/handle/10665/205923. Accessed on 2 April 2021.

2. Centers for Disease Control and Prevention (CDC) (2010) Progress toward control of rubella and prevention of congenital rubella syndrome worldwide. Morb Mortal Week Rep. 2009;59:130710 .
3. Cutts FT, Robertson SE, Diaz-Ortega JL, Samuel R. Control of rubella and congenital rubella syndrome (CRS) in developing countries, part 1: burden of disease from CRS. Bull World Health Organ. 1997;75:55-68.

4. Rubella vaccines: WHO position paper. Week Epidemiol Rec. 2011;86(29):301-16.

5. Yadav S, Gupta S, Kumari S. Sero-prevalence of rubella in women of reproductive age group. Indian $\mathbf{J}$ Pathol Microbiol. 1995;38(2):139-42.

6. Taneja DK, Sharma P. Targeting rubella for elimination. Indian J Public Health. 2012;56(4):26972.

7. Pooja D, Piyush G. Burden of congenital rubella syndrome (CRS) in India: a systematic review. Indian Pediatr. 2012;49(5):377-99.

8. Gupta E, Dar L, Broor S. Seroprevalence of rubella in pregnant women in Delhi, India. Indian J Med Res. 2006;123:833-5.

9. Singh MP, Arora S, Das A, Mishra B, Ratho RK. Congenital rubella and cytomegalovirus infections in and around Chandigarh. Indian J Pathol Microbiol. 2009;52:46-8.

10. Gupta A, Jain P, Jain A. Sero-prevalence of rubella virus antibodies in pregnant women in the vicinity of Luck now, Uttar Pradesh. Arch Med. 2015;7(3):7.

11. Jayakrishnan T, Murkoth A, George B, Rao B, Vidya $K$. Sero prevalence of rubella immunity in pregnant women in Kerala, India. Int J Med Public Health. 2016;6(4):189-92.

12. Muliyil DE, Singh P, Jois SK, Otiv S, Suri V, Varma $\mathrm{V}$, et al. Sero-prevalence of rubella among pregnant women in India, 2017. Vaccine. 2018;36(52):790912 .

13. Lambert N, Strebel P, Orenstein W, Icengelo J, Poland G. Rubella. Lancet. 2015;385(9984):2297-307.

14. Banatwala J, Brown D. Rubella. Lancet. 2004;363(9415):1127-37.

15. Rubella vaccines: WHO position paper. Week Epidemiol Rec. 2000,75(20):161-9.

16. Muhrekar M, Verma S, Singh K, Bavdekar A, Benakappa N, Santhanam S, et al. Epidemiology of congenital rubella syndrome (CRS) in India, 2016-18, based on data from sentinel surveillance. PLoS Negl Trop Dis. 2020;14(2):e0007982.

17. Winter AK, Pramanik S, Lessler J, Ferrari M, Grenfell BT, Metcalf CJE. Rubella vaccination in India: identifying broad consequences of vaccine introduction and key knowledge gaps. Epidemiol Infect. 2018;146:65-77.

18. Knox E. Strategy for rubella vaccination. Int $\mathbf{J}$ Epidemiol. 1980;9:13-23.

19. Ministry of Women and Child Development, Government of India. Rapid Survey on Children (2013-14): India and state factsheets, 2016. Available from: https://wcd.nic.in/acts/rapid-survey-childrenrsoc-2013-14. Accessed on 2 April 2021.

20. Introduction of Measles. Rubella vaccine guidelines (campaign and routine immunisation)-Operational guidelines. MoHFW, Government of India; 2017. 
21. Pandya HB, Zala P, Vala R, Vohra U, Walvekar O, Vagadia Y, et al. Seroprevalence of rubella immunity in rural pregnant women attending antenatal clinics at a tertiary care centre in Piparia, Gujarat, India. J Clin Diagn Res. 2021;15(2):DC01-4.
Cite this article as: Tripathy SR, Menon A, Bhardwaj B, Namaji MAAS, Khardenavis NA, Gupta N. Seroprevalence of rubella in pregnant women. Int J Reprod Contracept Obstet Gynecol 2021;10:4512-6. 